\title{
Flunarizine is more effective than topiramate in patients with chronic migraine and medication overuse headache
}

\author{
M Gracia-Naya ${ }^{\text {* }}$, N Hernando-Quintana ${ }^{1 *}$, MJ García-Gomara², S Sánchez-Valiente², C Ríos ${ }^{3}$, S Santos-Lasaosa ${ }^{4}$, \\ JA Mauri ${ }^{4}$, J Artal-Roy ${ }^{1}$, AM Latorre-Jimenez ${ }^{5}$
}

From The European Headache and Migraine Trust International Congress

London, UK. 20-23 September 2012

\section{Introduction}

Medication overuse headache $(\mathrm{MOH})$ implies secondary headache on a daily or near daily basis, for 15 days or more a month for 3 month and chronic migraine $\mathrm{CM}$ is the most common subtypes of $\mathrm{MOH}$ in speciality care [1]. Flunarizine and topiramate are considered as firstchoice drugs in prophylactic treatment of episodic or transformed migraine ${ }^{(2)}$. Topiramate is considered as first-choice drug in treatment of $\mathrm{CM}^{(3)}$.

\section{Objetives}

We analyze two independent case-series with $(\mathrm{CM})$ and $(\mathrm{MOH})$ according to ICHD-II criteria treated with topiramate or flunarizine as first intention and compare the results.

\section{Methods}

Patients were medication over users and naïve to (oral) prophylactic therapy. In both groups, the main effectiveness variables (reduction in the number of seizures and days with headache at four months of treatment and responder rates) were analysed.

\section{Results}

The study included 348 patients: 188 with flunarizine (88.2\% females; mean age: $43.8 \pm 13.6)$ and 160 with topiramate $(88.0 \%$ females; mean age: $40.2 \pm 13.2)$. No significant differences were found between groups as regards mean age, sex and number of migraines and days with headache in the previous month. There was a significant decrease $(0.0001)$ in the mean number of crisis in the fourth month of treatment, but with no significant difference between them: topiramate $(9.3 \pm 7.1$ to $4.6 \pm 6.1)$ and flunarizine $(9.9 \pm 7.3$ to $4.1 \pm 5.0)$. Mean of days with headaches at four month of treatment, topiramate $9.7 \pm 8.5$, flunarizine $6.9 \pm 8.4$ (.0106); the respondent rate was: topiramate $57.9 \%$, flunarizine $72.6 \%$ ( .0391$)$. The mean reduction in the number of days with headaches: topiramate $48.2 \%$, flunarizine $63.3 \%(.0040)$.

\section{Conclusions}

Both drugs showed effectiveness when used as the preferred drug in the preventive treatment of $(\mathrm{CM})$ and (HOM). Flunarizine offered better results on reduction in the number of days with headaches and minor side effects than topiramate.

\section{Author details}

${ }^{1}$ Hospital Miguel Servet, Spain. ${ }^{2}$ Hospital Royo Villanova, Spain. ${ }^{3}$ Hospital C. Barbastro, Spain. ${ }^{4}$ Hospital Clínico Zaragoza, Spain. ${ }^{5}$ Hospital San Jorge. Huesca, Spain.

Published: 21 February 2013

\section{Reference}

1. Headache Classification Committee, Olesen J, Bousser MG, Diener HC, Dodick D, First M, Goadsby PJ, et al: New appendix criteria open for a broader concept of chronic migraine. Cephalalgia 2006, 26:742-746.

doi:10.1186/1129-2377-14-S1-P202

Cite this article as: Gracia-Naya et al: Flunarizine is more effective than topiramate in patients with chronic migraine and medication overuse headache. The Journal of Headache and Pain 2013 14(Suppl 1):P202. 